\title{
CXCR1 Regulates Pulmonary Anti-Pseudomonas Host Defense
}

\author{
M. Carevic ${ }^{a}$ H. Öz ${ }^{a} \quad$ K. Fuchs ${ }^{f} \quad$ J. Laval $^{a}$ C. Schroth ${ }^{a} \quad$ N. Frey ${ }^{a}$
A. Hector ${ }^{a}$ T. Bilich ${ }^{a}$ M. Haug ${ }^{b}$
A. Schmidt ${ }^{b}$
S.E. Autenrieth ${ }^{c}$
K. Bucher ${ }^{d, e}$
S. Beer-Hammer ${ }^{d, e}$
A. Gaggarh
M. Kneilling ${ }^{f}$
C. Benarafaj J.L. Gao ${ }^{i}$
P.M. Murphy ${ }^{i}$
S. Schwarz ${ }^{\text {b }}$
B. Moepps ${ }^{9}$
D. Hartl ${ }^{a}$

${ }^{a}$ Children's Hospital and Interdisciplinary Center for Infectious Diseases, Departments of bedical Microbiology, 'Internal Medicine II and dPharmacology and Experimental Therapy, and eInterfaculty Center of Pharmacogenomics and Drug Research, University of Tübingen, ${ }^{f}$ Werner Siemens Imaging Center, Department of Preclinical Imaging and Radiopharmacy, Eberhard Karls University Tübingen, Tübingen, and 9 Institute of Pharmacology and

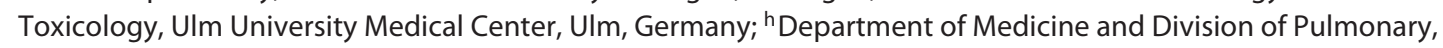
Allergy, and Critical Care Medicine, University of Alabama at Birmingham, Birmingham, Ala., and 'Molecular Signaling Section, Laboratory of Molecular Immunology, National Institute of Allergic and Infectious Diseases, $\mathrm{NIH}$,

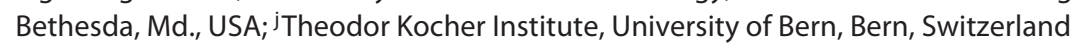

\section{Key Words}

CXCR1 - Chemokine receptors - Pseudomonas - Neutrophils . Cystic fibrosis $\cdot$ Toll-like receptor $5 \cdot$ Reactive oxygen species

\begin{abstract}
Pseudomonas aeruginosa is a key opportunistic pathogen causing disease in cystic fibrosis (CF) and other lung diseases such as chronic obstructive pulmonary disease (COPD). However, the pulmonary host defense mechanisms regulating anti- $P$. aeruginosa immunity remain incompletely understood. Here we demonstrate, by studying an airway $P$. aeruginosa infection model, in vivo bioluminescence imaging, neutrophil effector responses and human airway samples, that the chemokine receptor CXCR1 regulates pulmonary host defense against $P$. aeruginosa. Mechanistically, CXCR1 regulates anti-Pseudomonas neutrophil responses
\end{abstract}

\section{KARGER}

E-Mail karger@karger.com

www.karger.com/jin through modulation of reactive oxygen species and interference with Toll-like receptor 5 expression. These studies define CXCR1 as a novel, noncanonical chemokine receptor that regulates pulmonary anti-Pseudomonas host defense with broad implications for CF, COPD and other infectious lung diseases.

(c) 2016 S. Karger AG, Basel

\section{Introduction}

Chemokines recruit immune cells to inflammatory sites through binding to cognate G-protein-coupled chemokine receptors $[1,2]$. Chemokine receptor-mediated leukocyte migration is of particular relevance for infectious diseases to provide a cellular shield against invading pathogens. Neutrophils are the key effector cells of the innate immune system to combat bacterial and fungal in-
(C) 2016 S. Karger AG, Basel

$1662-811 X / 16 / 0084-0362 \$ 39.50 / 0$
Prof. Dr. Dominik Hartl

Children's Hospital and Interdisciplinary Center for Infectious Diseases University of Tübingen, Hoppe-Seyler-Strasse 1 DE-72076 Tübingen (Germany)

E-Mail dominik.hartl@med.uni-tuebingen.de 
fections, equipped with a variety of antimicrobial weapons [3-5]. Their physiological importance is exemplified in patients with neutropenia who suffer from life-threatening invasive bacterial infections.

While CC chemokines mainly act on mononuclear cells, neutrophils are primarily recruited by CXC chemokines to diseased microenvironments, particularly those binding CXCR1 and/or CXCR2, which are both highly expressed on the surface of neutrophils. Cxcr2 knock-out mice and small-molecule inhibitors have provided evidence that $\mathrm{Cxcr} 2$ mediates neutrophil migration to sites of inflammation and infection [6]. In contrast, the role of Cxcr1 remains enigmatic, owing to the lack of specific chemical inhibitors and the availability of $\mathrm{Cxcr1^{-/- }}$ mice [7]. Solving the crystal structure of CXCR1 has recently paved the way for the development of CXCR1-specific targeting compounds [8]. Several investigations have suggested a distinct and nonredundant role for CXCR1: the dual inhibition of CXCR1 and CXCR2 demonstrates substantial differences compared to selective inhibition of CXCR2 in different disease models, including cancer $[7,9]$, indicating a specific role for CXCR1. HIV has been found to bind to CXCR1 [10] and variants in the CXCR1 gene have been reported to modulate HIV disease activity [11] and cystic fibrosis (CF) [12], a fatal pulmonary disease characterized by neutrophilic airway inflammation and infections with the Gram-negative opportunistic pathogen Pseudomonas aeruginosa [13-17]. Besides its role in CF, P. aeruginosa colonizes airways from patients with chronic obstructive pulmonary disease (COPD) and causes severe nosocomial lung infections in immunocompromised individuals and ventilated patients in intensive care units. An efficient host defense against $P$. aeruginosa correlates with functional neutrophil responses in humans [18] and in mice [19], supporting the concept that neutrophils represent a major effector cell type in hostPseudomonas interactions. We demonstrated previously that loss of human CXCR1 on neutrophils in airway fluids from CF patients was associated with an impaired anti-Pseudomonas host defense ex vivo [20], suggesting indirectly that CXCR1 regulates host defense against $P$. aeruginosa.

Inspired by these previous findings, we sought to decipher the function of Cxcr1 in vivo in the context of pulmonary $P$. aeruginosa infection in a comprehensive manner using newly generated $C x c r 1$ knock-out mice. Here we demonstrate that Cxcr1 acts as a noncanonical chemokine receptor by regulating neutrophil-Pseudomonas interactions.

CXCR1 and Pseudomonas Host Defense

\section{Materials and Methods}

\section{Mouse Models}

Cxcr1 ${ }^{-1-}$ mice were generated by P. Murphy/NIH. Briefly, the Cxcrl gene was cloned from C57Bl/6 mouse genomic DNA. The targeting construct was created by replacement of the Cxcr1 gene with the neomycin resistance gene, homologous recombinants of the targeted deletion were generated in mouse embryonic stem cell line R1 and chimeric mice were produced by microinjection of recombinant embryonic stem cells into $\mathrm{C} 57 \mathrm{Bl} / 6$ blastocysts. The $\mathrm{CxCr}^{-1-}$ mice used in the experiments have been backcrossed to $\mathrm{C} 57 \mathrm{Bl} / 6$ mice for 11 generations. All animal studies were reviewed and approved by the Regierungspräsidium, Tübingen, Germany, and the Animal Care and Use Committee (ACUC) at NIAID, NIH, USA, and were carried out according to the guidelines of the German Law for the Protection of Animal Life. Mice were bred at the animal facility of the Institute of Pharmacology (Tübingen). Ageand sex-matched litter-mate controls were used for all experiments.

\section{Isolation of Bone Marrow Cells}

Negative selection of neutrophils from whole bone marrow cells was performed by Magnetic Cell Separation (MACS; Miltenyi Biotec) according to a previously published protocol, which allows isolation of highly purified primary untouched mouse neutrophils [21]. Briefly, bone marrow cells were flushed from the femur of mice and stained with the following anti-mouse antibodies (all biotinylated): CD5 (BD Biosciences), CD45R/B220 (BioLegend), CD49b/DX5, CD117, F4/80 (all eBioscience) and Ter 119 (BioLegend). After incubation, the unbound antibodies were washed away. Bone marrow cells were then incubated with magnetic beads (MACS, Miltenyi Biotec) labeled with streptavidin. Bead-coupled bone marrow cells were removed by immunomagnetic separation following the manufacturer's recommendation, resulting in highly purified neutrophils.

\section{Acute $P$. aeruginosa Infection}

The mouse model of acute pulmonary $P$. aeruginosa infection was performed as published recently by our group [22]. Mice were infected intranasally with the $P$. aeruginosa bacterial strain (PAO1) with doses ranging from $2 \times 10^{5}$ to $2 \times 10^{6} \mathrm{CFU}$, using established procedures [22]. Infections were carried out under antagonizable anesthesia. An inoculum of PAO1 was administered intranasally (50 $\mu \mathrm{l} /$ nostril). After infection, mortality and body weight were monitored once a day over 1 week. In vivo bioluminescence imaging was performed using a luciferase-expressing $P$. aeruginosa strain as published previously [23] and infecting mice with and $5 \times$ $10^{7} \mathrm{CFU}$ intratracheally. Bioluminescence imaging was performed $24 \mathrm{~h}$ after infection using an IVIS spectrum preclinical in vivo imaging read-out system (Perkin Elmer, Rodgau-Jügesheim, Germany).

\section{Flow Cytometry}

The panel of antibodies used to stain mouse bronchoalveolar lavage fluid (BALF), blood or bone marrow cells included F4/80 Pacific-blue (clone BM8), CD19-PerCP/Cy5.5 (clone 6D5) and CD3 brilliant violet (clone 17A2) from BioLegend, Siglec-F-PE (clone E50-2440), CD11b-PE-Cy7 (clone M1/70) and CD11c-APC-Cy7 (clone HL3) from BD Biosciences and Ly6G/C-APC (clone RB6$8 \mathrm{C} 5$ ) from eBioscience. Flow cytometry was performed using BD FACS Canto II flow cytometers (BD Biosciences), and data were 
analyzed with FlowJo software. A panel of autofluorescence, CD11b, CD11c, CD15, CD16 and MHC-II (all BD Biosciences) was used to analyze human neutrophils and dendritic cells. Anti-mouse Tolllike receptor 5 (TLR5)-Alexa Fluor 647 was from BioLegend (clone ACT5) and anti-human TLR5-FITC was from Imgenex/Novus (clone 19D759.2). Anti-mouse TLR4-PE (clone UT41) and anti-human TLR4-PE were from eBioscience (clone HTA125). Anti-human CXCR1-PE was from BD Biosciences (clone 5A12).

\section{Reactive Oxygen Species Production}

For the determination of reactive oxygen species (ROS) production, luminol-dependent chemiluminescence was used, which is an established method to measure intracellular ROS production [24]. For this purpose, $\mathrm{CxCr1^{+/+ }}$ and $\mathrm{CxCrI}^{-/-}$neutrophils were isolated from whole bone marrow as described above. The cells were used at a concentration of $2.5 \times 10^{5} / 100 \mu \mathrm{l}$ in Hank's balanced salt solution (HBSS) with $\mathrm{Ca}^{+} / \mathrm{Mg}^{+}$and immediately stimulated with recombinant chemokines (100 ng), flagellin (100 ng), PMA $(200 \mathrm{nM})$ or PAO1 $\left(2 \times 10^{6} / \mathrm{ml}\right)$ diluted in HBSS buffer containing $0.5 \mathrm{~mm}$ luminol (Sigma) and $120 \mu \mathrm{g} / \mathrm{ml}$ HRP. Chemiluminescence was measured at $37^{\circ} \mathrm{C}$ with a luminometer (Fluoroskan Ascent FL, ThermoScientific, Ascent software v2.6) for $19 \mathrm{~min}$.

\section{Neutrophil Transmigration}

We compared the chemotactic migration of neutrophils isolated from the bone marrow of age-matched $\mathrm{CxCr}^{+/+}$and $\mathrm{CxCr}^{-/-}$ mice towards recombinant $\mathrm{Cxcr} 1 / 2$ chemokines and the putative CXCR1/2-ligand acetylated proline-glycine-proline using an established in vitro transwell migration system with a $3-\mu \mathrm{m}$ pore size, as described previously in detail $[25,26]$.

\section{Bacteria}

P. aeruginosa wild-type strains (PAO1) were used as published previously by our group [22]. Strains of the culture collection were streaked on agar plates and incubated at $37^{\circ} \mathrm{C}$ overnight. Colonies were then inoculated into tryptic soy broth overnight. The next day, a 1:100 dilution in tryptic soy broth was performed and bacteria were cultured at $37^{\circ} \mathrm{C}$ for $4 \mathrm{~h}$. The optical density was measured at $600 \mathrm{~nm}$. A GFP-expressing P. aeruginosa strain was used for microscopical imaging studies. A luciferase-expressing $P$. aeruginosa strain was used for bioimaging studies as published previously [23].

\section{Neutrophil-Pseudomonas Interactions}

Bone marrow-isolated $\mathrm{Cxcr} 1^{+/+}$and $\mathrm{Cxcrl}^{-/-}$neutrophils $(5 \times$ $10^{5}$ ) were coincubated with opsonized PAO1 at MOI 50 for 7 or 60 min (RPMI 1640, 10\% FCS) with shaking at $50 \mathrm{rpm}$. The contents of each well were centrifuged $(500 \mathrm{~g}, 10 \mathrm{~min})$ and then washed twice with HBSS (Gibco). To assess extracellular killing, supernatants were harvested and plated in triplicate onto Pseudomonas isolation agar plates. To assess intracellular killing, neutrophil pellets were treated with gentamicin $(400 \mu \mathrm{g} / \mathrm{ml})$ to ensure that extracellular and cell surface-associated bacteria were removed. Cells were washed twice in PBS, lysed with ice-cold water, and then plated in triplicate onto Pseudomonas isolation agar plates. For microscopical analyses, bacteria were stained using the LIVE/DEAD BacLight ${ }^{\mathrm{TM}}$ bacterial viability kit according to the manufacturer's instructions (Life Technologies, ThermoFisher) utilizing mixtures of SYTO 9 green-fluorescent nucleic acid stain and the red-fluorescent nucleic acid stain, propidium iodide. SYTO 9 labels bacteria with intact membranes and those with damaged membranes, while propidium iodide penetrates only bacteria with damaged membranes, causing a reduction in the SYTO 9 stain fluorescence when both dyes are present. After fixation (in $4 \%$ formaldehyde for $10 \mathrm{~min}$ at room temperature), total bacteria (living and dead) were quantified using fluorescence microscopy. For image acquisition, a Leica DMRE microscope and an HCX PL APO ×100 (NA 1.35) oil objective was used.

\section{Asthma Mouse Models}

Ovalbumin and house dust mite murine asthma models were performed as published previously by our group [27].

Bronchoalveolar Lavage Fluid

BALF was obtained and processed as published previously by our group [27].

\section{Colony-Forming Units}

Lungs were removed and homogenized in $1 \mathrm{ml}$ PBS. Samples were serially diluted and plated on agar media for CFU counts overnight.

\section{Optical Imaging}

We measured in vivo luciferase expression using the IVIS spectrum optical imaging system. Noninvasive in vivo optical imaging measurements were conducted $24 \mathrm{~h}$ after intratracheal infection of $\mathrm{CxCrI}^{-1-}$ and $\mathrm{CxCrI}^{+/+}$mice with luciferase-expressing $P$. aeruginosa bacteria (TBCF10839 isogenic mutant D8A6, $5 \times 10^{7} \mathrm{CFU} /$ mouse) as published previously [23]. During measurements, mice were anesthetized by inhalation of isoflurane- $\mathrm{O}_{2}(1.5 \%$ Forane, Abbott GmbH, Wiesbaden, Germany) and body temperature was maintained at $37^{\circ} \mathrm{C}$. Regions of interest (ROIs) were drawn on the right and left lung of $\mathrm{CxCr1^{-/- }}$ and $\mathrm{CxCr1^{+/+ }}$ mice, which allows the semiquantitative analysis of the average radiance $\left[\mathrm{p} / \mathrm{s} / \mathrm{cm}^{2} / \mathrm{sr}\right]$ of the bioluminescence to be performed. Image analyses were performed using Living Image software (Perkin Elmer).

\section{Experimental Peritonitis}

Peritonitis was initiated by injection of $0.7 \mathrm{ml}$ of sterile aged $4 \%$ thioglycollate broth intraperitoneally $4 \mathrm{~h}$ before harvest. The peritoneum was lavaged with $10 \mathrm{ml}$ of PBS and cells were counted by flow cytometry as described above.

\section{Patients}

BALF was analyzed from patients with non-CF chronic bronchitis ( $\mathrm{n}=5$, mean age 22 years, with no $P$. aeruginosa infection) or from CF patients with chronic $P$. aeruginosa infections $(n=5$, mean age 20 years) as described previously in detail $[20,22]$. CXCR1 and TLR5 surface expression levels (mean fluorescence intensity, MFI) were quantified on airway/BALF dendritic cells $\left(\mathrm{CD} 11 \mathrm{~b}^{+}\right.$autofluorescence $\left.{ }^{\text {low }} \mathrm{CD} 11 \mathrm{c}^{\text {high }} \mathrm{MHC}-\mathrm{II}^{\text {high }}\right)$ or neutrophils $\left(\mathrm{CD} 11 \mathrm{~b}^{+} \mathrm{CD} 15^{+} \mathrm{CD} 16^{+}\right)$from patients with bronchitis or $\mathrm{CF}$ and $P$. aeruginosa infections. The study was approved by the Institutional Review Board/Ethical Committee of the University of Tübingen and meets the standards of the Declaration of Helsinki. Informed consent was obtained from all study subjects.

\section{Statistics}

All calculations were performed using GraphPad Prism v6.0 software. Statistical significance $(\mathrm{p}<0.05)$ was determined using the Mann-Whitney U test or by ANOVA. 


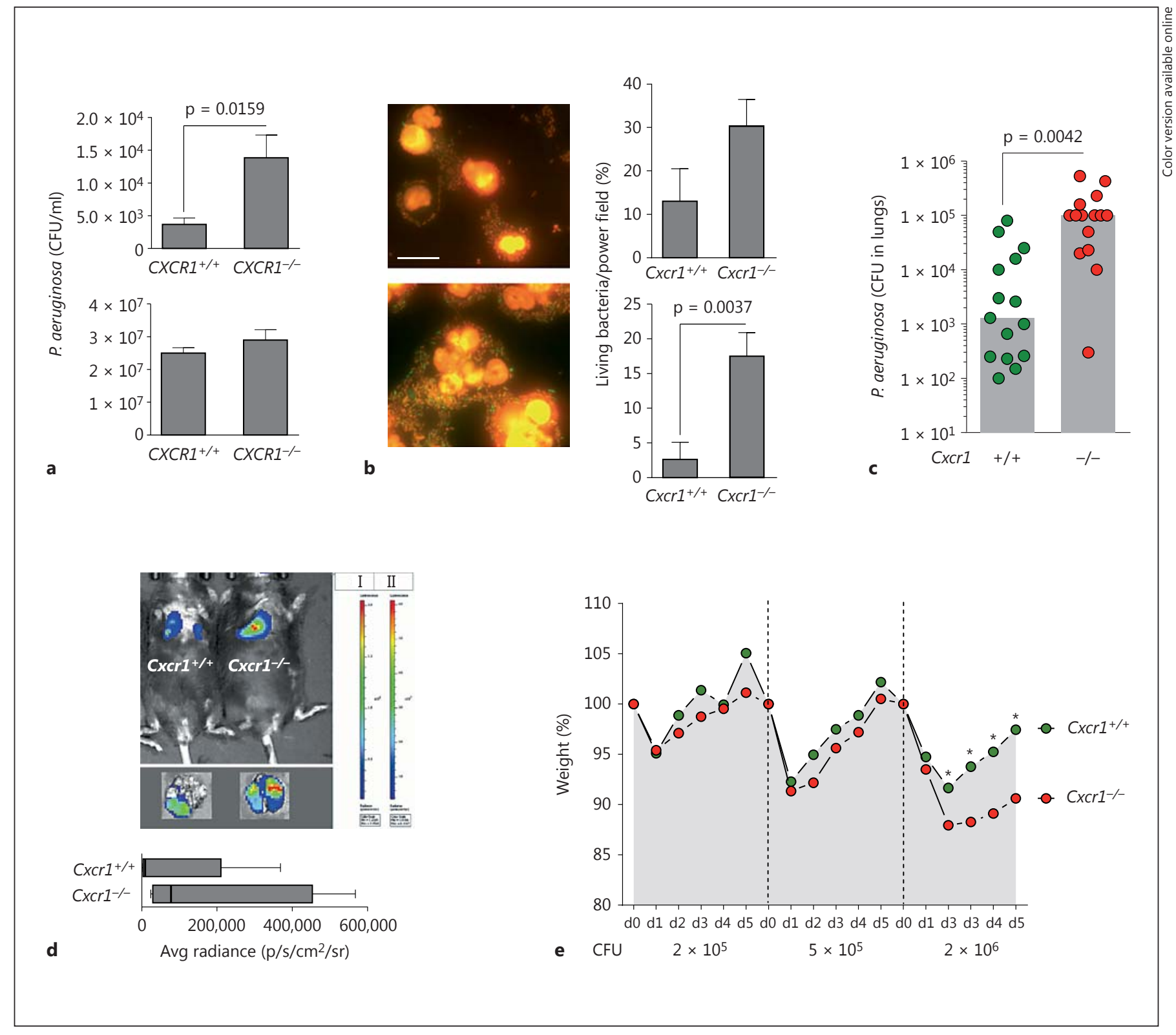

Fig. 1. $P$. aeruginosa infections. a Intracellular killing (upper panel) and extracellular killing (lower panel). Bone marrow-isolated neutrophils from age- and sex-matched $\mathrm{Cxcrl}^{+/+}$and $\mathrm{CxCrI}^{-/-}$mice were infected with PAO1 for $60 \mathrm{~min}$ at MOI 50, and CFU were counted. Data are from 5 independent experiments (means, SEMs). b GFP-PAO1 bacteria and bone marrow-isolated neutrophils from age- and sex-matched $\mathrm{CxCr1^{+/+ }}$ and $\mathrm{Cxcr} 1^{-/-}$mice were coincubated for 7 or $60 \mathrm{~min}$ at MOI 50. Bacteria were stained using a live/dead bacterial staining kit (left) and quantified microscopically (right). Representative images of $\mathrm{CxCr}^{+/+}$(upper left) and $\mathrm{CxCr1}^{-1-}$ (lower left) neutrophils $60 \mathrm{~min}$ after GFP-PAO1 infection are shown. Living bacteria are shown in green and dead bacteria in red. Scale bar: $10 \mu \mathrm{m}$. Bars show percentages of living bacteria at $7 \mathrm{~min}$ (upper right) and $60 \mathrm{~min}$ (lower right) at MOI 50. Data are from 5 independent experiments (means, SEMs). c-e Age- and sex-matched $\mathrm{Cxcr} 1^{+/+}$and $\mathrm{Cxcr}^{-/-}$mice were infected intranasally $(\mathbf{c}, \mathbf{e})$ or intratracheally (d) with PAO1 (except for d, luciferaseexpressing TBCF10839 isogenic mutant D8A6). Lung CFU (c), bacterial lung in vivo clearance (d) and weight loss (e) were monitored. For these experiments, $2 \times 10^{6} \mathrm{CFU}(\mathbf{c}), 5 \times 10^{7}(\mathbf{d})$ or $2 \times$ $10^{5}$ to $2 \times 10^{6} \mathrm{CFU}$ PAO1 (e) were inoculated. c Bars represent medians; CFU were quantified in lungs $12 \mathrm{~h}$ after infection. $\mathbf{d}$ Bioluminescence imaging was performed $24 \mathrm{~h}$ after the infection for $5\left(\mathrm{Cxcrl}^{+/+}\right)$or $4\left(\mathrm{CxCr1}^{-/-}\right)$independent experiments; box and whiskers (range: $\min / \max$, quartiles, medians) are shown. e Mean weight points for days $0-5(\mathrm{~d} 0-\mathrm{d} 5)$ are shown. ${ }^{*} \mathrm{p}<0.05 \mathrm{CXCr}^{+/+}$ versus $C x \mathrm{Cr}^{-/-}$mice. 


\section{Results}

\section{Cxcr1 Regulates Anti-Pseudomonas Host Defense}

Since we observed in previous studies that CXCR1 is involved in the antibacterial host defense functions of human neutrophils in vitro and associated with $P$. aeruginosa infections in patients with CF ex vivo $[12,20]$, we systematically investigated the role of Cxcrl by employing $P$. aeruginosa in vivo infection models. We started with quantifying the capacity of isolated $\mathrm{Cxcrl}^{-/-}$and $\mathrm{Cxcr}^{+/+}$neutrophils to kill $P$. aeruginosa bacteria in vitro by using traditional CFU assays (fig. 1a) as well as by bacterial live/dead imaging methods (fig. 1b). These studies demonstrated that $\mathrm{CxCr1^{-/- }}$ neutrophils were impaired in intracellular, but not extracellular killing of $P$. aeruginosa bacteria compared to their wild-type counterparts (fig. 1a, b). Next, we interrogated this bacterial clearance defect in vivo and used a well-established $P$. aeruginosa lung infection model. These studies confirmed our in vitro findings and demonstrated that $\mathrm{Cxcr} 1^{-/-}$mice were impaired in clearing $P$. aeruginosa from their lungs with an average of 100 -fold higher bacterial loads in the lungs of $\mathrm{Cxcrl}^{-/-}$ mice compared to age- and gender-matched $\mathrm{CxCr}^{+/+}$ mice (fig. 1c). To visualize and quantify this impairment in bacterial clearance in a more refined spatiotemporal manner, we used a recently described in vivo bioluminescence imaging system (fig. 1d) [23]. These studies confirmed that $\mathrm{CxCrI}^{-/-}$mice were impaired in clearing $P$. aeruginosa from their pulmonary compartment compared to age- and gender-matched $\mathrm{Cxcr}^{+/+}$mice (fig. 1d). By inoculating different increasing doses of $P$. aeruginosa into the airways, we found that this clearance defect led to a dose-dependent higher morbidity (as quantified by weight loss) in $\mathrm{Cxcr}^{-/-}$mice compared to age- and gender-matched $\mathrm{Cxcrl}^{+/+}$mice (fig. 1e), with significant differences for the $P$. aeruginosa CFU of $2 \times 10^{6}$, but without significant differences at lower CFU.

To exclude the possibility that the impaired pulmonary host-defense in $\mathrm{Cxcr}^{-/-}$mice is a mere reflection of an underlying basal defect in neutrophil homeostasis, we quantified total cells and neutrophils in bone marrow and peripheral blood and studied their apoptosis and necrosis ex vivo. These studies demonstrated that neither total cell counts nor total neutrophil counts in bone marrow (online suppl. fig. S1A; for all online suppl. material, see www.karger.com/doi/10.1159/000444125) or peripheral blood (online suppl. fig. S1B) differed significantly between age-matched $\mathrm{CxCr}^{+/+}$and $\mathrm{Cxcr}{ }^{-/-}$mice. Percentages of neutrophils in bone marrow (online suppl. fig. S1A) were significantly increased in $\mathrm{Cxcrl}^{-/-}$compared to $\mathrm{Cxcr}{ }^{+/+}$mice, but there was no significant difference in neutrophil percentages in peripheral blood between $\mathrm{CxCr}^{+/+}$and $\mathrm{CxCr}^{-/-}$mice (online suppl. fig. S1B). Neutrophil survival studies demonstrated that neutrophil overall survival or neutrophil apoptosis did not differ between wild-type and knock-out animals, while there was a tendency towards less necrosis in $\mathrm{Cxcrl}^{-/-}$neutrophils compared to $\mathrm{CxCr}^{+/+}$neutrophils (online suppl. fig. S1C).

\section{Cxcr1 Modulates ROS Production}

Next, we sought to dissect the mechanisms by which Cxcr1 regulates pulmonary anti- $P$. aeruginosa host defenses. Since the production of ROS is a key mechanism by which neutrophils kill bacteria, we compared ROS production between $\mathrm{CxCrI}^{-/-}$and $\mathrm{CxCrI}^{+/+}$mice. These studies demonstrated that bone marrow cells isolated from $\mathrm{Cxcr1^{-1- }}$ mice produced lower amounts of ROS upon stimulation with the recombinant chemokine CXCL8 compared to bone marrow cells from $\mathrm{Cxcr} 1^{+/+}$ mice (fig. 2a). Since $P$. aeruginosa is a flagellated bacterium and several previous studies have shown that flagellin represents a key pathogen-associated molecular pattern, which is essential for innate immune cell activation, we tested the effect of flagellin on ROS production by $\mathrm{CxCrI}^{-/-}$and $\mathrm{CxCr} 1^{+/+}$bone marrow myeloid cells. These studies demonstrated that, in line with CXCL8, Cxcr1 $1^{-/}$ myeloid cells also showed impaired ROS production upon stimulation with bacterial flagellin compared to bone marrow myeloid cells from $\mathrm{Cxcr}^{+/+}$mice (fig. 2a). To further investigate whether these ROS changes in the myeloid compartment in $\mathrm{CxCr}^{+/+}$mice were specifically due to neutrophils, we isolated bone marrow neutrophils. These studies consistently demonstrated that highly purified isolated $\mathrm{Cxcrl}^{-/-}$neutrophils, similar to nonfractionated bone marrow cells, produced lower amounts of ROS compared to their $\mathrm{CxCr}^{+/+}$counterparts upon stimulation with the chemokine CXCL8 (fig. 2b), whole PAO1 or bacterial flagellin. We further extended these studies and included other Cxcr1/Cxcr2 chemokine receptor ligands into these assays. These studies demonstrated that Cxcr1 ${ }^{-/-}$neutrophils showed a similar, albeit to a lesser extent than CXCL8, ROS impairment towards the putative Cxcr1 ligand Cxcl5 (LIX) as well as the recombinant chemokines Cxcl1 (KC) and Cxcl2 (MIP-2) (fig. 2b). Comparative analyses at the kinetic end point after neutrophil stimulation for all applied stimulants showed that ROS production by $\mathrm{CxCr}^{-/-}$neutrophils was significantly impaired towards CXCL8, Cxcl1, Cxcl5, flagellin and $P$. aeruginosa, but not $\mathrm{Cxcl} 2$ stimulation (fig. $2 \mathrm{c}, \mathrm{d}$ ). In 


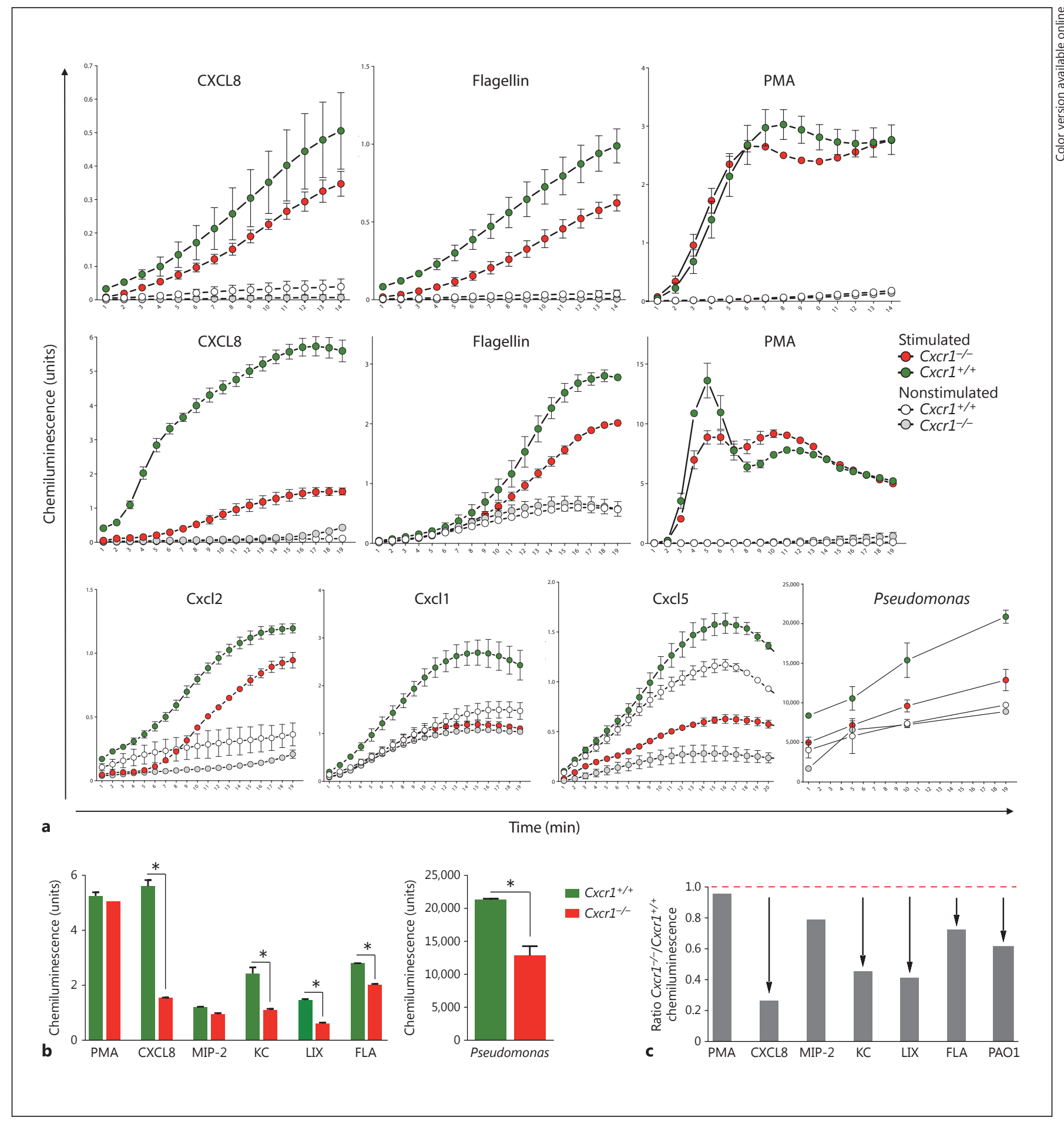

Fig. 2 ROS. Total bone marrow cells (a, top row) or neutrophils isolated from bone marrow (a, middle and bottom rows) of ageand sex-matched $C x c r 1^{+/+}$and $C x \mathrm{CrI}^{-/-}$mice were stimulated with recombinant chemokines (all at $100 \mathrm{ng}$ ), flagellin (100 ng), PMA $(200 \mathrm{nM})$ or PAO1 bacteria $\left(2 \times 10^{6} / \mathrm{ml}\right)$. ROS production was measured using chemiluminescence. Bar graph plots of stimulated
$\mathrm{CxCr}^{+/+}$versus $\mathrm{CxCr1^{-/- }}$ neutrophils, as absolute chemiluminescence units (medians, IQRs, b) or ratio of $\mathrm{CxCr1}^{-/-}$to $\mathrm{Cxcr1^{+/+ }}$ neutrophils (c). Asterisks (b) or arrows $(\mathbf{c})$ denote $\mathrm{p}<0.05, \mathrm{Cxcr}^{+/+}$ versus $C x \mathrm{Cr}^{-/-}$neutrophils. FLA $=$Flagellin; $\mathrm{KC}=\mathrm{Cxcl} 1$; LIX = Cxcr1 ligand Cxcl5; MIP-2 = Cxcl2. 

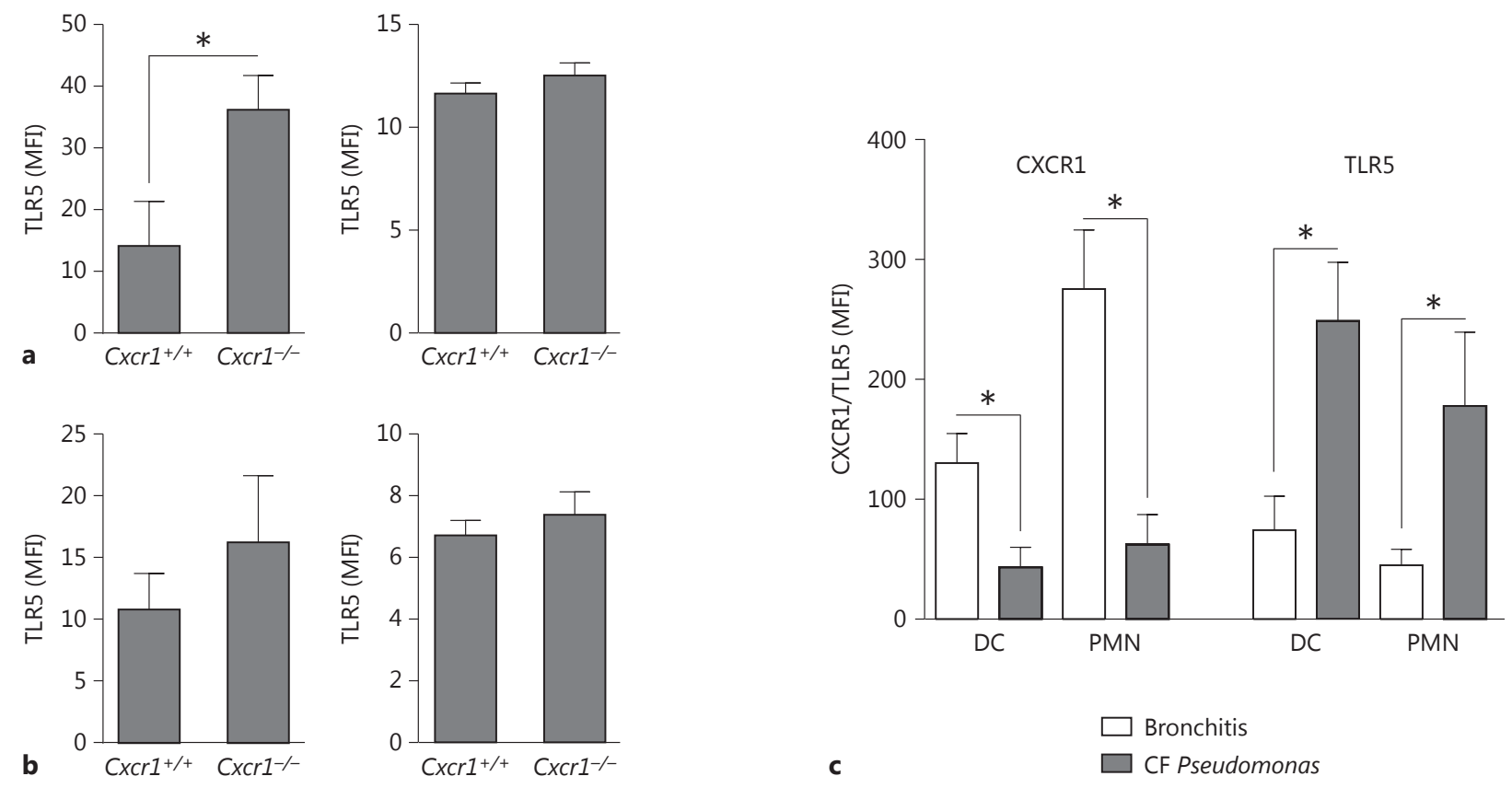

Fig. 3. TLR5 surface expression (MFI) was quantified on airway/ BALF (a) or bone marrow (b) dendritic cells (left panel) or neutrophils (right panel) from age- and sex-matched $\mathrm{Cxcr} 1^{+/+}$ and $C x c r 1^{-/-}$mice. ${ }^{*} \mathrm{p}<0.05 \mathrm{Cxcr} 1^{+/+}$versus $C x \mathrm{Cr}^{-/-}$neutrophils. c CXCR1 and TLR5 surface expression (MFI) was quantified on airway/BALF dendritic cells (DC) or neutrophils (PMN) from patients with bronchitis or CF and P. aeruginosa infections. ${ }^{*} \mathrm{p}<0.05$ bronchitis versus CF Pseudomonas. contrast to specific stimulation with chemokines, $P$. aeruginosa or bacterial flagellin, nonspecific stimulation with the phorbol ester PMA did not elicit a differential ROS production in unfractionated bone marrow myeloid cells (fig. 2a) or isolated neutrophils from $\mathrm{CxCr}^{+/+}$and $\mathrm{Cxcr}^{-/-}$mice (fig. 2b-d), suggesting that Cxcr1-mediated ROS production is chemokine- and $P$. aeruginosa-dependent, rather than reflecting a redundant and universal basal ROS impairment. Collectively, these studies demonstrate that Cxcr1 mediates anti- $P$. aeruginosa host defense in neutrophils through a mechanism involving ROS production.

\section{Cxcr1 Modulates TLR5 Expression}

Since generation of ROS is a universal antimicrobial host defense mechanism and not specifically related to $P$. aeruginosa infections, we next investigated the role of TLR5 as a key pattern recognition receptor in $P$. aeruginosa-associated lung infections, such as CF [28-32]. These studies demonstrated that genetic abrogation of
Cxcr1 led to an upregulation of Tlr5 surface expression on airway dendritic cells upon acute $P$. aeruginosa infection (fig. 3a), whereas no changes were found on airway neutrophils (fig. 3a) or bone marrow dendritic cells or neutrophils (fig. 3b). To assess the human disease relevance of these findings, we analyzed TLR5 expression on airway immune cells in patients with $\mathrm{CF}$ and $P$. aeruginosa infection, characterized by a loss of CXCR1 [20]. These investigations demonstrated that both dendritic cells and neutrophils (fig. 3c) in the airways of CF patients with $P$. aeruginosa infection showed a loss of CXCR1 paralleled by a concomitant upregulation of TLR5 surface expression on the respective cell types compared to non-CF bronchitis patients without $P$. aeruginosa infection. No significant difference in TLR4 expression levels was noted between $\mathrm{CxCr} 1^{+/+}$and $\mathrm{CxCr} 1^{-/-}$ neutrophils ( $\mathrm{p}>0.05$ ) or between CF patients with $P$. aeruginosa infection and non-CF bronchitis patients without $P$. aeruginosa infection $(\mathrm{p}>0.05$, data not shown). When viewed in combination, these studies in- 
Fig. 4. Neutrophil recruitment was evaluated in vivo (a-d) and in vitro (e). a-d Total cells (left panel), percentage of neutrophils (middle panel) or total numbers of neutrophils (right panel) were quantified in age- and sex-matched $\mathrm{CxCr}^{+/+}$and $\mathrm{CxCr}^{-1-}$ mice using murine models of PAO1 lung infection (a), thioglycollate-induced peritonitis (b), ovalbumin-induced allergic airway inflammation (c) and house dust mite-induced allergic airway inflammation (d). PF = Peritoneal fluid. e Neutrophils isolated from bone marrow of ageand sex-matched $\mathrm{CxCrI}^{+/+}$and $\mathrm{Cxcr1} \mathrm{I}^{-/-}$ mice were stimulated with the indicated chemokines (100 ng, acetylated prolineglycine-proline, $1 \mu \mathrm{M}$ ) and underwent a transwell-based chemotactic migration assay for $120 \mathrm{~min}$. The relative migration of $\mathrm{CxCr1}^{-/-}$compared to $\mathrm{Cxcr} 1^{+/+}$neutrophils is shown $(=100 \%$, red line). All bars represent medians. $\mathrm{KC}=\mathrm{Cxcl} 1$; MIP-2 = $\mathrm{Cxcl} 2$; PGP = proline-glycine-proline.
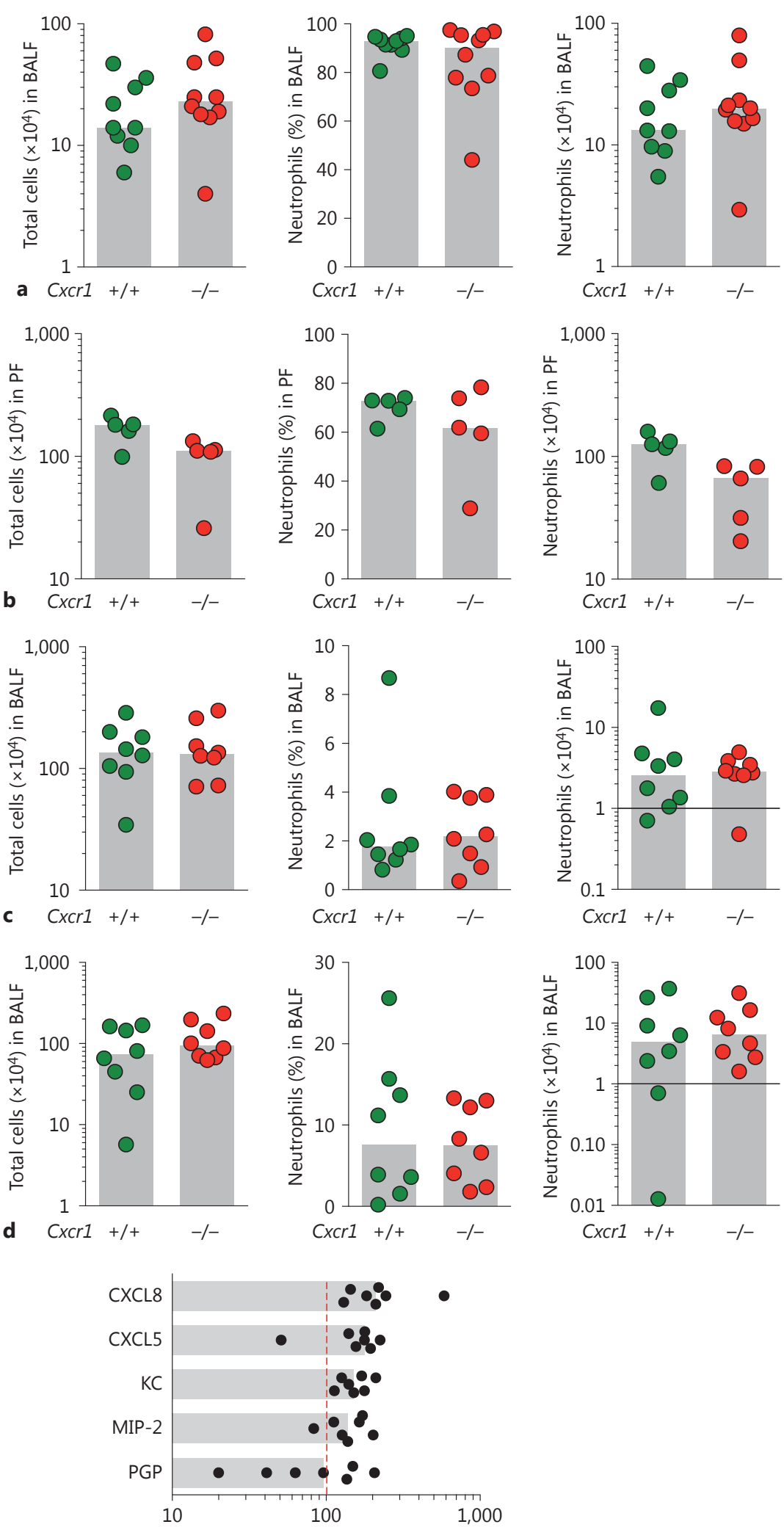

e Change in chemotactic migration related to $\mathrm{CXCr}^{+/+}(\%)$ 
dicate that a loss of CXCR1 in mice or human CF patients is associated with an upregulation of TLR5 expression on immune cells in the airways.

\section{Cxcr1 Is Dispensable for Neutrophil Migration}

Since CXCR1 belongs to the family of chemokine receptors that primarily orchestrate leukocyte recruitment, we analyzed whether neutrophil migration is impaired in inflammatory settings in $\mathrm{Cxcr} 1^{-/-}$mice in vivo and by using isolated $\mathrm{CxCr}^{-/-}$neutrophils in vitro. To assess neutrophil migration in an in vivo setting, we compared neutrophil transmigration into the bronchoalveolar space upon $P$. aeruginosa lung infection in $\mathrm{Cxcr}^{+/+}$and $\mathrm{CxCr}^{-/-}$mice. These studies demonstrated that neutrophils from $\mathrm{Cxcr}^{-/-}$mice were equally potent in bronchoalveolar infiltration compared to their wild-type counterparts (fig. 4a). To investigate whether this phenomenon is restricted to the pulmonary compartment or is common at inflammatory sites in general, we compared $\mathrm{CxCrI}^{+/+}$and $\mathrm{CxCr}^{-/-}$neutrophil transmigration in a thioglycollate-induced peritonitis model. These studies demonstrated a tendency of $\mathrm{Cxcr}^{-/-}$neutrophils towards a lower peritoneal infiltration compared to matched $\mathrm{Cxcrl}^{+/+}$neutrophils, which was, however, not statistically significant (fig. 4b). To further assess whether Cxcr1 modulates noninfectious neutrophil transmigration differentially, we compared $\mathrm{CxCr} 1^{+/+}$and $\mathrm{CxCr}^{-/-}$neutrophil bronchoalveolar recruitment in 2 different models of allergic airway inflammation, namely ovalbumin-induced (fig. 4c) and house dust mite-induced airway inflammation (fig. 4d). These studies consistently demonstrated that $\mathrm{CxCrI}^{-/-}$neutrophils showed no impairment in migrating into the bronchoalveolar compartment upon noninfectious allergic airway inflammation.

To precisely investigate the migratory characteristics of $\mathrm{CxCrI}^{+/+}$and $\mathrm{Cxcr}^{-/-}$neutrophils in vitro, we compared the chemotactic migration of neutrophils isolated from bone marrow from age-matched $\mathrm{Cxcrl}^{+/+}$and $\mathrm{Cxcr}^{-/-}$mice towards $\mathrm{Cxcr} 1 / 2$ chemokines using a transwell migration system $[25,26]$. Consistent with our in vivo findings, these in vitro studies demonstrated that $\mathrm{CxCr}^{-/-}$neutrophils were not impaired in migrating to CXCR1/2 chemokines, but even rather showed a tendency towards a more efficient chemotactic migration, particularly towards recombinant CXCL8, which has been previously described to activate Cxcr1 [33] (fig. 4e). Taken together, these studies demonstrate that Cxcr 1 is dispensable for neutrophil migration in infectious and noninfectious conditions in vitro and in vivo.

\section{Discussion}

While traditionally chemokines and their receptors have been limited to their role in leukocyte recruitment, a growing body of evidence suggests that these G-proteincoupled receptors have much broader roles in regulating physiological and pathophysiological processes at several levels $[1,34,35]$. Here, we demonstrate that the chemokine receptor Cxcr1 is dispensable for neutrophil transmigration under infectious and sterile inflammatory conditions, but regulates ROS production and TLR5 surface expression as critical bacterial sensing (TLR5) and killing (ROS) mechanisms. This cellular effector mechanism has disease relevance, as genetic deficiency of CXcrl increases the susceptibility towards $P$. aeruginosa infections, which are a significant mortality factor in patients with CF or individuals with immunosuppression or on ventilation.

A variety of studies have analyzed the role of CXCR2 in vivo, supporting the concept that CXCR2 mediates neutrophil migration to sites of inflammation $[6,36]$. In contrast, the role of Cxcr1 in vivo has not been defined so far due to a lack of a murine knock-out mouse model. Here, we provide evidence, inspired by our previous human data and mechanistic in vitro studies [12, 20,37], that $\mathrm{Cxcr1^{-/- }}$ mice show an impaired pulmonary neutrophilic host defense against $P$. aeruginosa, mediated through a ROS- and TLR5-mediated mechanism. Moreover, our studies demonstrate that neutrophil migration to the pulmonary site of inflammation and infection is not impaired in $\mathrm{CxCr}^{-/-}$mice. Therefore, in contrast to CXCR2, which is primarily involved in neutrophil recruitment, Cxcr1, based on our data, is dispensable for neutrophil recruitment but mediates neutrophil effector functions by a mechanism involving ROS and TLR5. The underlying subcellular pathways remain to be elucidated, but our studies highlight the notion that chemokine receptors play a broader role in leukocyte biology than mediating cell migration by regulating antimicrobial effector and bacterial sensing mechanisms.

Previous studies on human patients with CF who suffer from chronic $P$. aeruginosa infection showed that CXCR1/2 polymorphisms modulate the disease outcome of these patients [12]. Furthermore, previous studies at the cellular and ex vivo level provided indirect evidence that human IL-8R1 (CXCR1), but not IL-8R2 (CXCR2), is involved in NADPH oxidase and phospholipase D activation [38] and anti- $P$. aeruginosa host defense functions [20]. Our in vivo studies confirm and extend these findings by demonstrating that Cxcr1 plays a novel and noncanonical role in host-pathogen interactions by regu- 
lating neutrophil ROS effector response without affecting neutrophil recruitment, homeostasis or survival. Since ROS are essential for host defense against a variety of bacterial pathogens beyond $P$. aeruginos $a$, these findings may have broad implications for infectious diseases. Moreover, ROS have been implicated in the proinflammatory harmful activities in chronic disease conditions, such as cardiovascular and chronic lung diseases [39, 40], suggesting that interfering with CXCR1 pharmacologically may have the potential to dampen oxidative stress in chronic diseases in vivo.

In contrast to CXCR2, which mediates neutrophil transmigration in vitro and in vivo, our studies strongly support the notion that Cxcr1 does not mediate neutrophil migration. Conversely, $\mathrm{Cxcr1^{-/- }}$ neutrophils showed even a higher migratory potential in transwell assays in vitro, mainly towards the 2 putative Cxcr 1 ligands $\mathrm{Cxcl} 5$ and CXCL8. While we have currently no explanation for this observation, we are tempted to speculate that, in line with previous findings in other CXC chemokine receptors, Cxcr1 may serve as a negative regulator of Cxcl5and/or CXCL8-triggered leukocyte migration by acting as decoy receptor. An alternative hypothesis is that of CXCR1/CXCR2 heterodimerization [41], suggesting that the loss of Cxcr1 could have an impact on Cxcr2 receptor surface expression on neutrophils. While we observed no significant differences in Cxcr2 MFI surface expression levels between $\mathrm{CxCr}^{+/+}$and $\mathrm{CxCr}^{-/-}$neutrophils (online suppl. fig. 2A), we found moderately increased percentages of $\mathrm{Cxcr}^{+}$neutrophils in the bone marrow of $\mathrm{Cxcrl}^{-/-}$compared to $\mathrm{CxCr1^{+/+ }}$ mice (online suppl. fig. $2 \mathrm{~B}$ ), suggesting that the observed tendency towards a higher migratory capacity of $\mathrm{CxCr}^{-1-}$ neutrophils in vitro could be due to a relative increase of $\mathrm{Cxcr}^{+}$ neutrophils. Moreover, the loss of Cxcr1 receptors probably also increases the availability of Cxcr1/Cxcr2 ligands for Cxcr2 binding. However, in-depth biochemical and pharmacological analyses would be required to dissect this interaction, which was beyond the scope of this study.

Beyond the involvement of ROS and Tlr5, the precise cellular mechanism(s) by which Cxcr1 is involved in anti$P$. aeruginosa neutrophil activities remains elusive. Our in vitro read-out system provided evidence for an impaired intracellular, but not extracellular, killing capacity of $\mathrm{CxCr}^{-/-}$neutrophils. Based on this finding and the fact that we did not observe signs of neutrophil extracellular trap formation in our short-term in vitro assay systems, we speculate that the Cxcr1-mediated antibacterial mechanism in our experimental system mainly involved ROS- dependent intracellular phagocytic killing. Since our studies were, however, restricted to $P$. aeruginosa, we cannot exclude the possibility that $\mathrm{Cxcr} 1$ differentially regulates antimicrobial effector mechanisms depending on the type of pathogen.

We found that $\mathrm{CxCr}^{-/-}$neutrophils were impaired in generating ROS in response to $P$. aeruginosa or bacterial flagellin, whereas no difference was observed in response to nonbacterial generic ROS activation by stimulation with PMA. These findings inspired us to investigate the interaction of CXCR1 and flagellin-sensing pathways in mice and CF patients with $P$. aeruginosa infections. Our studies indicated that a loss of CXCR1 in mice or human CF patients leads to an upregulation of the flagellin receptor TLR 5 on the surface of immune cells in the infected airways. Based on these findings, we speculate that in neutrophil- $P$. aeruginosa interactions, CXCR1 collaborates with TLR5 to efficiently combat $P$. aeruginosa. When CXCR1 is abrogated, this bacterial sensing (TLR5) and killing (ROS) mechanism is impaired, leading to uncontrolled $P$. aeruginosa infections. Previous studies provided evidence for a TLR-chemokine receptor cross-talk in lipid rafts in monocytes and macrophages in response to the Gram-negative bacterium Porphyromonas gingivalis [42]. The precise subcellular CXCR1/TLR5 interaction mechanisms in neutrophil- $P$. aeruginosa host defense remain to be dissected in future studies.

A clear limitation of our study, regarding the human disease translation, is the $P$. aeruginosa infection model that we used, which reflects acute pneumonia rather than chronic infective disease as is found in CF or COPD airways. However, our primary aim was to define the role of Cxcr1 in anti- $P$. aeruginosa host defense as a proof-ofprinciple in vivo using a well-established infection model, while chronic infection/colonization models were beyond our scope and have to be investigated in future studies. Some further aspects of our study remained poorly defined and should be investigated in the future. (1) What is the underlying reason for the difference in bone marrow neutrophils between $\mathrm{CxCr} 1^{-/-}$and $\mathrm{CxCrI}^{+/+}$mice? (2) Are differential chemokines released by $\mathrm{CxCr}^{-/-}$and $\mathrm{CxCr}^{+/+}$neutrophils that could directly (as shown previously in the human system for the chemokine CXCL6 [43, 44]) or indirectly (through auto/paracrine effects) affect bacterial killing? (3) What is the underlying mechanism behind the upregulation of Tlr5 on $\mathrm{CxCr}^{-/-}$dendritic cells? Are TLR5-ROS interactions involved? [45] (4) What are the intracellular Cxcr1-downstream pathways regulating neutrophil effector responses? 
In summary, our studies demonstrate that CXCR1 regulates anti- $P$. aeruginosa host defense through a ROSand TLR5-mediated mechanism. Beyond CF, these findings may have broader implications for other P. aeruginosa-associated pulmonary disease conditions, such as COPD or ventilator-associated pneumonia. Moreover, our results point towards caution in targeting chemokine receptors [46] without considering their so far underappreciated antimicrobial roles.

\section{Acknowledgements}

We thank Antje Munder and Burkhard Tümmler, MHH Hannover Germany, for luciferase-expressing $P$. aeruginosa bacteria. This work was supported by the German Research Foundation (DFG, Emmy Noether Programme HA 5274/3-1 to D.H.), the Fritz-Thyssen-Foundation (A.H. and D.H.), the CRC685 at Tübingen and the Novartis Foundation (D.H.). This work was supported in part by the Division of Intramural Research, National Institute of Allergy and Infectious Diseases, National Institutes of Health, USA (P.M.M. and J.L.G.).

\section{Disclosure Statement}

The authors have declared that no conflict of interest exists.

\section{References}

1 Griffith JW, Sokol CL, Luster AD: Chemokines and chemokine receptors: positioning cells for host defense and immunity. Annu Rev Immunol 2014;32:659-702.

2 Moser B, Loetscher P: Lymphocyte traffic control by chemokines. Nat Immunol 2001;2: 123-128.

-3 Amulic B, Cazalet C, Hayes GL, Metzler KD, Zychlinsky A: Neutrophil function: from mechanisms to disease. Annu Rev Immunol 2012;30:459-489.

4 Nauseef WM, Borregaard N: Neutrophils at work. Nat Immunol 2014;15:602-611.

5 Kruger P, Saffarzadeh M, Weber AN, Rieber N, Radsak M, von Bernuth $H$, Benarafa C, Roos D, Skokowa J, Hartl D: Neutrophils: Between host defence, immune modulation, and tissue injury. PLoS Pathog 2015; 11:e1004651.

6 Reutershan J: CXCR2 - the receptor to hit? Drug News Perspect 2006;19:615-623.

7 Russo RC, Garcia CC, Teixeira MM, Amaral FA: The CXCL8/IL-8 chemokine family and its receptors in inflammatory diseases. Expert Rev Clin Immunol 2014;10:593-619.

8 Park SH, Das BB, Casagrande F, Tian Y, Nothnagel HJ, Chu M, Kiefer H, Maier K, De Angelis AA, Marassi FM, Opella SJ: Structure of the chemokine receptor CXCR1 in phospholipid bilayers. Nature 2012;491:779-783.

\9 Citro A, Cantarelli E, Maffi P, Nano R, Melzi R, Mercalli A, Dugnani E, Sordi V, Magistretti P, Daffonchio L, Ruffini PA, Allegretti M, Secchi A, Bonifacio E, Piemonti L: CXCR1/2 inhibition enhances pancreatic islet survival after transplantation. J Clin Invest 2012;122: 3647-3651.

10 Giagulli C, Magiera AK, Bugatti A, Caccuri F, Marsico S, Rusnati M, Vermi W, Fiorentini S, Caruso A: HIV-1 matrix protein p17 binds to the IL-8 receptor CXCR1 and shows IL-8-like chemokine activity on monocytes through RHO/ROCK activation. Blood 2012;119: 2274-2283.

\section{Vasilescu A, Terashima Y, Enomoto M, Heath S, Poonpiriya V, Gatanaga H, Do H, Diop G, Hirtzig T, Auewarakul P, Lauhakirti D, Sura T, Charneau P, Marullo S, Therwath A, Oka S, Kanegasaki S, Lathrop M, Matsu- shima K, Zagury JF, Matsuda F: A haplotype of the human CXCR1 gene protective against rapid disease progression in HIV-1+ pa- tients. Proc Natl Acad Sci USA 2007;104: 3354-3359. \\ 12 Kormann MS, Hector A, Marcos V, Mays LE, Kappler M, Illig T, Klopp N, Zeilinger S, Carevic M, Rieber N, Eickmeier O, Zielen S, Gaggar A, Moepps B, Griese M, Hartl D: CXCR1 and CXCR2 haplotypes synergisti-} cally modulate cystic fibrosis lung disease. Eur Respir J 2012;39:1385-1390.

13 Lyczak JB, Cannon CL, Pier GB: Establishment of Pseudomonas aeruginosa infection: lessons from a versatile opportunist. Microbes Infect 2000;2:1051-1060.

14 Lavoie EG, Wangdi T, Kazmierczak BI: Innate immune responses to Pseudomonas aeruginosa infection. Microbes Infect 2011;13: 1133-1145.

15 Gomez MI, Prince A: Opportunistic infections in lung disease: Pseudomonas infections in cystic fibrosis. Curr Opin Pharmacol 2007; 7:244-251.

16 Hoiby N: Recent advances in the treatment of Pseudomonas aeruginosa infections in cystic fibrosis. BMC Med 2011;9:32.

17 Brugha RE, Davies JC: Pseudomonas aeruginosa in cystic fibrosis: pathogenesis and new treatments. Br J Hosp Med (Lond) 2011;72: 614-619.

18 Kragh KN, Alhede M, Jensen PO, Moser C, Scheike T, Jacobsen CS, Seier Poulsen S, Eickhardt-Sorensen SR, Trostrup H, Christoffersen L, Hougen HP, Rickelt LF, Kuhl M, Hoiby N, Bjarnsholt T: Polymorphonuclear leukocytes restrict growth of Pseudomonas aeruginosa in the lungs of cystic fibrosis patients. Infect Immun 2014;82:4477-4486.
19 De Simone M, Spagnuolo L, Lore NI, Rossi G, Cigana C, De Fino I, Iraqi FA, Bragonzi A: Host genetic background influences the response to the opportunistic Pseudomonas aeruginosa infection altering cell-mediated immunity and bacterial replication. PLoS One 2014;9:e106873.

20 Hartl D, Latzin P, Hordijk P, Marcos V, Rudolph C, Woischnik M, Krauss-Etschmann S, Koller B, Reinhardt D, Roscher AA, Roos D, Griese M: Cleavage of CXCR1 on neutrophils disables bacterial killing in cystic fibrosis lung disease. Nat Med 2007;13:1423-1430.

21 Hasenberg M, Kohler A, Bonifatius S, Borucki K, Riek-Burchardt M, Achilles J, Mann L, Baumgart K, Schraven B, Gunzer M: Rapid immunomagnetic negative enrichment of neutrophil granulocytes from murine bone marrow for functional studies in vitro and in vivo. PLoS One 2011;6:e17314.

- 22 Hector A, Schafer H, Poschel S, Fischer A, Fritzsching B, Ralhan A, Carevic M, Oz H, Zundel S, Hogardt M, Bakele M, Rieber N, Riethmueller J, Graepler-Mainka U, Stahl M, Bender A, Frick JS, Mall M, Hartl D: Regulatory $\mathrm{T}$ cell impairment in cystic fibrosis patients with chronic Pseudomonas infection. Am J Respir Crit Care Med 2015;191:914923.

23 Munder A, Wolbeling F, Klockgether J, Wiehlmann L, Tummler B: In vivo imaging of bioluminescent Pseudomonas aeruginosa in an acute murine airway infection model. Pathog Dis 2014;72:74-77.

24 Bylund J, Bjornsdottir H, Sundqvist M, Karlsson A, Dahlgren C: Measurement of respiratory burst products, released or retained, during activation of professional phagocytes. Methods Mol Biol 2014;1124:321-338.

25 Bloes DA, Otto M, Peschel A, Kretschmer D: Enterococcus faecium stimulates human neutrophils via the formyl-peptide receptor 2 . PLoS One 2012;7:e39910. 
-26 Kretschmer D, Gleske AK, Rautenberg M, Wang R, Koberle M, Bohn E, Schoneberg T, Rabiet MJ, Boulay F, Klebanoff SJ, van Kessel KA, van Strijp JA, Otto M, Peschel A: Human formyl peptide receptor 2 senses highly pathogenic Staphylococcus aureus. Cell Host Microbe 2010;7:463-473.

-27 Mays LE, Ammon-Treiber S, Mothes B, Alkhaled M, Rottenberger J, Muller-Hermelink ES, Grimm M, Mezger M, Beer-Hammer $\mathrm{S}$, von Stebut E, Rieber N, Nurnberg B, Schwab M, Handgretinger R, Idzko M, Hartl D, Kormann MS: Modified FOXp3 mRNA protects against asthma through an IL-10-dependent mechanism. J Clin Invest 2013;123: 1216-1228.

28 Descamps D, Le Gars M, Balloy V, Barbier D, Maschalidi S, Tohme M, Chignard M, Ramphal R, Manoury B, Sallenave JM: Tolllike receptor 5 (TLR5), IL-1 beta secretion, and asparagine endopeptidase are critical factors for alveolar macrophage phagocytosis and bacterial killing. Proc Natl Acad Sci USA 2012;109:1619-1624.

29 Morris AE, Liggitt HD, Hawn TR, Skerrett SJ: Role of toll-like receptor 5 in the innate immune response to acute $P$. aeruginosa pneumonia. Am J Physiol Lung Cell Mol Physiol 2009;297:L1112-L1119.

-30 Koller B, Kappler M, Latzin P, Gaggar A, Schreiner M, Takyar S, Kormann M, Kabesch M, Roos D, Griese M, Hartl D: TLR expression on neutrophils at the pulmonary site of infection: TLR1/TLR2-mediated up-regulation of TLR5 expression in cystic fibrosis lung disease. J Immunol 2008; 181:2753-2763.

- 31 Blohmke CJ, Victor RE, Hirschfeld AF, Elias IM, Hancock DG, Lane CR, Wilcox PG, Smith KD, Overhage J, Hancock REW, Turvey SE: Innate immunity mediated by TLR5 as a novel anti-inflammatory target for cystic fibrosis lung disease. J Immunol 2008; 180 : 7764-7773.

32 Zhang Z, Louboutin JP, Weiner DJ, Goldberg JB, Wilson JM: Human airway epithelial cells sense Pseudomonas aeruginosa infection via recognition of flagellin by toll-like receptor 5 . Infect Immun 2005;73:7151-7160.

33 Fan X, Patera AC, Pong-Kennedy A, Deno G, Gonsiorek W, Manfra DJ, Vassileva G, Zeng M, Jackson C, Sullivan L, Sharif-Rodriguez W, Opdenakker G, Van Damme J, Hedrick JA, Lundell D, Lira SA, Hipkin RW: Murine CXCR1 is a functional receptor for GCP-2/ CXCL6 and interleukin-8/CXCL8. J Biol Chem 2007;282:11658-11666.

34 Fricker SP, Metz M: Chemokine receptor modeling: an interdisciplinary approach to drug design. Future Med Chem 2014;6:91114.

35 Roy I, Evans DB, Dwinell MB: Chemokines and chemokine receptors: update on utility and challenges for the clinician. Surgery 2014; 155:961-973.

36 Konrad FM, Reutershan J: CXCR2 in acute lung injury. Mediators Inflamm 2012;2012: 740987.

37 Bakele M, Lotz-Havla AS, Jakowetz A, Carevic M, Marco V, Munta AC, Gerstin SW, Hartl D: An interactive network of elastase, secretases, and $\mathrm{PAR}-2$ protein regulates CXCR1 receptor surface expression on neutrophils. J Biol Chem 2014;289:20516-20525.

- 38 Jones SA, Wolf M, Qin S, Mackay CR, Baggiolini M: Different functions for the interleukin 8 receptors (IL-8R) of human neutrophil leukocytes: NADPH oxidase and phospholipase D are activated through IL-8R1 but not IL-8R2. Proc Natl Acad Sci USA 1996;93: 6682-6686
39 Lambeth JD: NOX enzymes, ROS, and chronic disease: an example of antagonistic pleiotropy. Free Radic Biol Med 2007;43: 332-347.

40 Langen RC, Korn SH, Wouters EF: ROS in the local and systemic pathogenesis of COPD. Free Radic Biol Med 2003;35:226-235.

-41 Martinez Munoz L, Lucas P, Navarro G, Checa AI, Franco R, Martinez AC, RodriguezFrade JM, Mellado M: Dynamic regulation of CXCR1 and CXCR2 homo- and heterodimers. J Immunol 2009;183:7337-7346.

42 Hajishengallis G, Wang M, Liang S, Triantafilou M, Triantafilou K: Pathogen induction of CXCR4/TLR2 cross-talk impairs host defense function. Proc Natl Acad Sci USA 2008; 105:13532-13537.

43 Linge HM, Collin M, Nordenfelt P, Morgelin M, Malmsten M, Egesten A: The human CXC chemokine granulocyte chemotactic protein 2 (GCP-2)/CXCL6 possesses membrane-disrupting properties and is antibacterial. Antimicrob Agents Chemother 2008;52:25992607.

44 Jovic S, Linge HM, Shikhagaie MM, Olin AI, Lannefors L, Erjefalt JS, Morgelin M, Egesten A: The neutrophil-recruiting chemokine GCP-2/CXCL6 is expressed in cystic fibrosis airways and retains its functional properties after binding to extracellular DNA. Mucosal Immunol 2016;9:112-123.

45 Joo JH, Ryu JH, Kim CH, Kim HJ, Suh MS, Kim JO, Chung SY, Lee SN, Kim HM, Bae YS, Yoon JH: Dual oxidase 2 is essential for the toll-like receptor 5-mediated inflammatory response in airway mucosa. Antioxid Redox Signal 2012;16:57-70.

46 Owen C: Chemokine receptors in airway disease: which receptors to target? Pulm Pharmacol Ther 2001;14:193-202. 